\title{
XPS, XRD and Laser Raman Analysis of Surface Modified of 6150 Steel Substrates for the Deposition of Thick and Adherent Diamond-like Carbon Coatings
}

\author{
William de Melo Silva*, José Rubens Gonçalves Carneiro ${ }^{\mathrm{a}}$,Vladimir Jesus Trava-Airoldi ${ }^{\mathrm{b}}$ \\ ${ }^{a}$ Department of Mechanical Engineering, Pontifical Catholic University of Minas Gerais - PUC Minas, \\ CEP 30535-901, Belo Horizonte, MG, Brazil \\ ${ }^{\mathrm{b}}$ Associate Laboratory of Sensors and Materials, National Institute for Space Research, CEP 12227-010, \\ São José dos Campos, SP, Brazil
}

Received: November 1, 2012; Revised: December 5, 2012

\begin{abstract}
Although the 6150 steel has an excellent fatigue and impact resistance, it is unsuitable to operate it when the corrosion is a limited factor. We propose here a sequence of steel pre-treatment by carburizing, carbonitriding and nitriding in order to improve the poor adhesion between Diamond Like-Carbon coatings on steel. This sequence is our attempt to reduce the difference between the coefficients of thermal expansion of steel and DLC through the graded interface. This work demonstrates the quantitative analysis of the molecules present at surface using X-ray photoelectron spectroscopy. The crystallographic structures are investigated by X-ray diffraction which shows the formation of carbides and nitride phases. Raman spectroscopy reveals the carburizing surface characteristics where DLC coating is nucleated and grown at the substrate. At the end of the analysis it is possible to verify which molecules and phases are formed on the steel surface interface after each step of pre-treatment.
\end{abstract}

Keywords: diamond-like carbon, adhesion, nitriding, scratching test, plasma enhanced chemical vapor deposition

\section{Introduction}

In recent decades, many studies in surface engineering have sought the development of coating technology on steel substrate. Coatings that provide wear protection combining reduced friction, self-lubrication and resistance to chemical reactions. A promising coating that has these properties is the Diamond-like carbon (DLC) due to its interesting properties such as wear resistance and low friction. Applications of this coating can be self-lubricating devices $^{1}$, micro-electromechanical ${ }^{2}$, read-write heads ${ }^{3,4}$ and biomedical prosthetic implants ${ }^{5}$. DLC coatings can be made by different deposition methods such as magnetron sputtering $^{6}$ and chemical vapor deposition ${ }^{7}$. The difficulty of DLC adhesion is due its high residual internal stress during formation ${ }^{8-10}$, however, another problem is the thermal expansion coefficients of DLC, $1 \times 10^{-6} / \mathrm{K}$, while the steel is $\sim 11.8 \times 10^{-6}-14.7 \times 10^{-6} / \mathrm{K}$. These factors limit the DLC coating adherence on steel substrate. Results of previous studies showed that the maximum DLC coating thickness is less than $0.25 \mu \mathrm{m}$ on untreated steel surfaces ${ }^{11}$. Many studies have carried out that DLC coating thicker than $0.5 \mu \mathrm{m}$ can be synthesized by interlayer formed between coating and substrate ${ }^{12-15}$. Although the 6150 steel has an excellent fatigue and impact resistance at moderate hardness, it is unsuitable to operate it when the corrosion is a limited factor. Actually, it should be used only for short run die applications. In order to avoid the effects of wear by oxidation, it is reasonable coating the steel with a coating

*e-mail: williammelosilva@gmail.com of high hardness, wear resistance, corrosion and chemical resistance as DLC. In this work, it is showed our study of DLC thickness limitation by subjecting the steel substrate to a series of pre-treatments prior to DLC deposition ${ }^{16}$. Here, it was used a pulsed DC plasma-enhanced chemical vapor deposition system to produce a graded interface, beginning with the steel substrate, followed by a carbonitrided layer, then a carburized layer, and finally DLC coating. Within this process, we can not ignore the oxidation effects of the steel surface considerably affect the properties of the interface. In addition, the gradual transition from steel to DLC through an intermediate carbon-containing region reduces the thermal expansion coefficient mismatch at the DLC-substrate interface and thus the thermal stress. A side benefit of the pre-treatment process is to produce a harder substrate, which increases the load-carrying capacity ${ }^{17-19}$.

\section{Material and Methods}

All surface pre-treatments and depositions were performed in a pulsed DC plasma-enhanced chemical vapor deposition (PECVD) system. The steel substrate was mounted on a water-cooled $50 \mathrm{~mm}$ diameter cathode, which was biased by an asymmetrical bipolar pulsed DC source, consisting of fixed positive pulse amplitude of $30 \mathrm{~V}$ followed by a variable negative pulse with peak amplitude ranging from -250 to $-900 \mathrm{~V}$ at $20 \mathrm{kHz}^{[16]}$. According to the manufacturer, the tensile strength of SAE 6150 steel after the normalizing heat treatment is $1.4 \mathrm{GPa}$ and the alloy composition is shown in 
Table 1. The surface that received coating was polished using standard metallographic techniques down to one-micron diamond paste and then degreased in an ultrasonic bath before introduction into the deposition chamber. The substrate was first cleaned in an argon discharge for ten minutes. The pre-treatment of surfaces and DLC deposition were performed in a sequence of 5 steps ${ }^{16}$ :

(1) The steel substrate was subjected to a carbonitriding plasma treatment, in a $250 \mathrm{~Pa}$ mixture of methane, hydrogen and nitrogen (flow rate ratio of $5: 15: 80$ ) at $475^{\circ} \mathrm{C}$ for 2 hours. The steel sample after this step will be labeled as $\mathrm{CN} 1$;

(2) While keeping the total pressure and temperature constants, the relative flow rates were changed to methane:hydrogen:nitrogen $=15: 5: 80$ (i.e., increasing the methane content at the expense of hydrogen). This step was continued for 1 hour. The steel sample after these two steps will be labeled as $\mathrm{CN} 2$;

(3) The gas mixture was changed to methane and hydrogen (flow rate ratio of 60:40), thus changing this to a carburizing treatment. This step was performed at $250 \mathrm{~Pa}$ and $475^{\circ} \mathrm{C}$ for 0.5 hours. The steel sample after these three steps will be labeled as $\mathrm{CNC}$;

(4) The total pressure and temperature were reduced to $40 \mathrm{~Pa}$ and $150{ }^{\circ} \mathrm{C}$ respectively, while keeping the methane/hydrogen ratio constant. This step continued for 1 hour to thermally equilibrate the system. The steel sample after these three steps will be labeled as CNCE;

(5) At the end of those four steps, DLC deposition followed, operating with pure methane at $40 \mathrm{~Pa}$ and $150{ }^{\circ} \mathrm{C}$ for 1.5 hours. Pulsed DC power was applied throughout the four steps of surface reatment and coating deposition ${ }^{16}$.

We used X-ray diffraction Philips PW1840 system to analyze the carbide and nitride phases formed by different surface pre-treatments. XPS technique surface analysis was performed using a spectrometer model UNI-SPECS UHV. It was possible to analyze the composition and structure of SAE 6150 steel surface modified. The base pressure of the system was lower than $6.10 \mathrm{~Pa}$ when used $\mathrm{Mg} \mathrm{K} \alpha$ line ( $\mathrm{h} v=1253.6 \mathrm{eV}$ ) and the energy step of the analyzer was adjusted to $10 \mathrm{eV}$. The noise spectra of inelastic core $\mathrm{C} 1 \mathrm{~s}, \mathrm{O} 1 \mathrm{~s}, \mathrm{~N} 1 \mathrm{~s}, \mathrm{Fe}_{2} \mathrm{~d}_{3 / 2}$ and $\mathrm{Al} 2 \mathrm{p}$ was subtracted using the Shirley method for functions. The composition of the surface layer was determined by the proportions of the peaks areas on factors corrected by the sensitivity (Scoffield) of the corresponding elements. The spectra were deconvoluted using the following function, Voigt with combinations Gaussian $(70 \%)$ and Lorentzian (30\%). The width at half height ranged between 1.6 and $2.1 \mathrm{eV}$, the accuracy in determining the composition varies by $\pm 5 \%$ and the position of the peaks were determined to within $\pm 0.1 \mathrm{eV}$. Renishaw 2000 Raman system with an Ar-ion laser (wavelength $=514 \mathrm{~nm}$ ) in the backscatter geometry to obtain Raman spectra of the surface after various surface treatments and deposition. Spectral fittings of the $\mathrm{G}$ and $\mathrm{D}$ bands were performed using two Gaussian functions to obtain the $I_{D} / I_{G}$ intensity ratio ${ }^{20}$. Microscopy images were obtained by scanning electron microscopy (SEM) Hitachi S-3400 VP-SEM system. The adhesion of the DLC coating was qualitatively determined by a nano-scratch test (Micro Materials). In this test, a diamond Berkovich tip (radius 8.8 micron) was slid across the sample at $1 \mu \mathrm{m} / \mathrm{s}$. The load was increased at $1 \mathrm{mN} / \mathrm{sec}$ until $300 \mathrm{mN}$. The onset of delamination and the length of the scratch track were determined by SEM examination of the scratched surface. The length of the scratch track and the load at which the tip undergoes sudden downward displacement due to coating delamination provides two estimates of the critical load, which is used as a relative measure of coating adhesion.

\section{Results and Discussions}

\subsection{X-ray diffraction structure analysis}

Figure 1 shows x-rays diffraction patterns obtained from the steel substrate subjected to four pre-treatments described before. The SAE 6150 steel substrate as received, used here has diffraction at peaks $44^{\circ}$ and $64^{\circ}{ }^{\circ 10,16]}$. It can be seen that the pre-treatment of surface modified the structure due to the displacement of peaks and the appearance of substantial peak intensity at $38^{\circ}$. The $\alpha-F e$ peak at $46^{\circ[21]}$ has been evident between $\mathrm{CN} 1$ and $\mathrm{CNC}$, so that after the slow cooling treatment (CNCE) happened an increase in intensity. Nitrogen (N) steel diffusion changed the steel surface composition, the evidence of this is the formation of phases as $\mathrm{Fe}_{2-3} \mathrm{~N}$ and $\mathrm{Fe}_{4} \mathrm{~N}^{[22,23]}$. Based on the comparison with patterns powder diffraction pattern, it can be concluded that the new phases arise as a result of carburizing and carbonitriding pre-treatments.

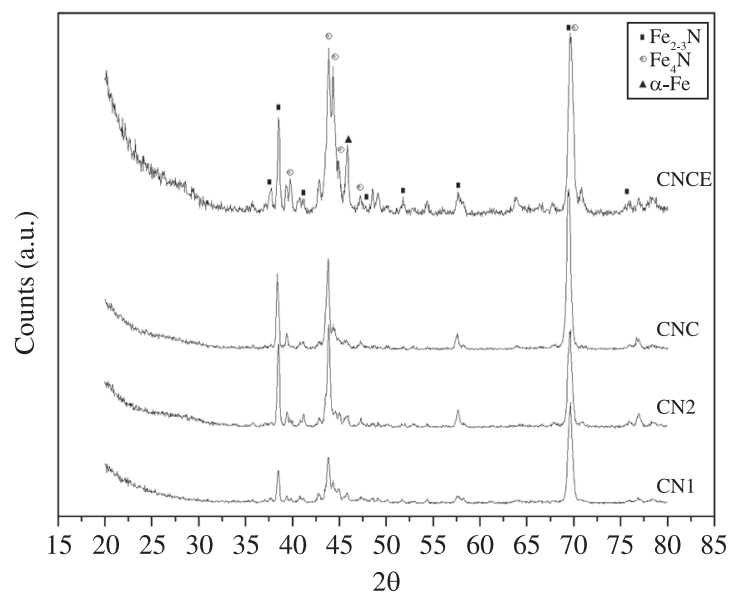

Figure 1. X-ray diffraction patterns obtained from the substrate subjected to four pre-treatments with patterns from reference materials.

Table 1. Chemical composition of the steel substrate (SAE 6150).

\begin{tabular}{cccccccc}
\hline Element & $\mathbf{C}$ & $\mathbf{M n}$ & $\mathbf{P}$ & $\mathbf{S}$ & $\mathbf{S i}$ & $\mathbf{C r}$ & $\mathbf{V}$ \\
\hline wt. $\%$ & $0.48-0.55$ & $0.65-0.9$ & $<0.04$ & $<0.04$ & $0.20-0.35$ & $0.50-1.10$ & $0.1-0.15$ \\
\hline
\end{tabular}




\subsection{XPS surface analysis}

A technique for surface modifications of PECVD, used here, is caused by chemical interactions among species with the surface of the steel occurring intensively in the first atomic layers of the substrate. XPS was used in order to analyze the first surface thickness of $3 \mathrm{~nm}$. The low concentrations $(<0.1 \%)$ of vanadium $(\mathrm{V})$, chromium $(\mathrm{C})$, manganese $(\mathrm{M})$ and sulfur $(\mathrm{S})$ were not detected in the SAE 6150 steel. Due to the content according to carbonitriding and carburizing treatments, there was an increase of carbon content at the steel surface which it can be seen in Figure 2. Figure 3 represents the XPS extended spectrum of each sample which showed that the low $\mathrm{N}$ content

Sample- CN1

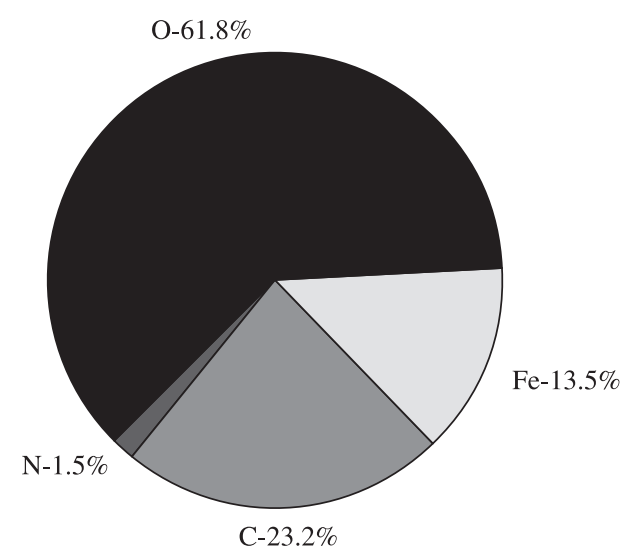

Sample - CNC

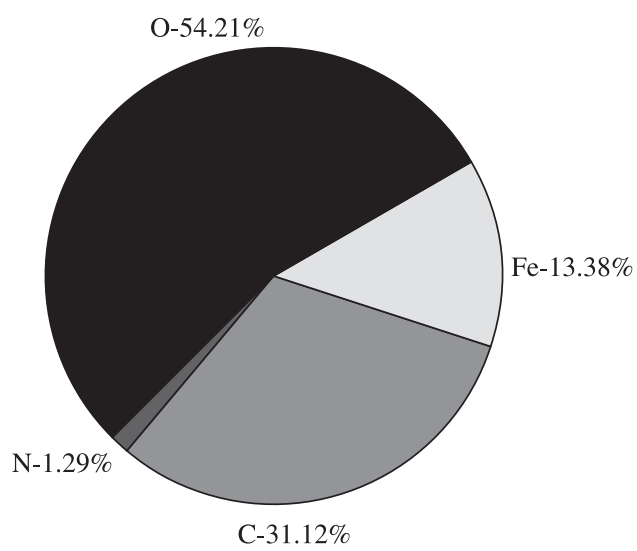

remains constant in all samples. In general, the presence of carbon $(\mathrm{C})$, oxygen $(\mathrm{O}), \mathrm{N}$ and iron $(\mathrm{Fe})$ are shown at the surface independently of treatment variations, as in Table 2, which contains molecule percent bonding of each chemical element in the sample surface detected on the extended spectrum ${ }^{24}$. The chemical elements in the surface presented at XPS spectra of specific bonding energy of each element is capable of providing information and possible species of the chemical bonds on the sample surface ${ }^{25,26}$. It was observed that the concentration of carbon and nitrogen contained in the samples indicate that it was formed a $\mathrm{CN}_{\mathrm{x}}$ film on the steel. Structural surface modifications occurred by the diffusion of $\mathrm{C}$, and the steel surface layer induced

Sample - CN2

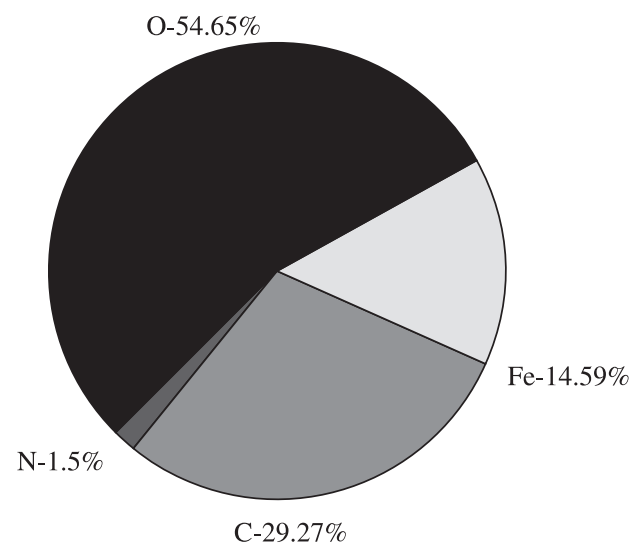

Sample - CNCE

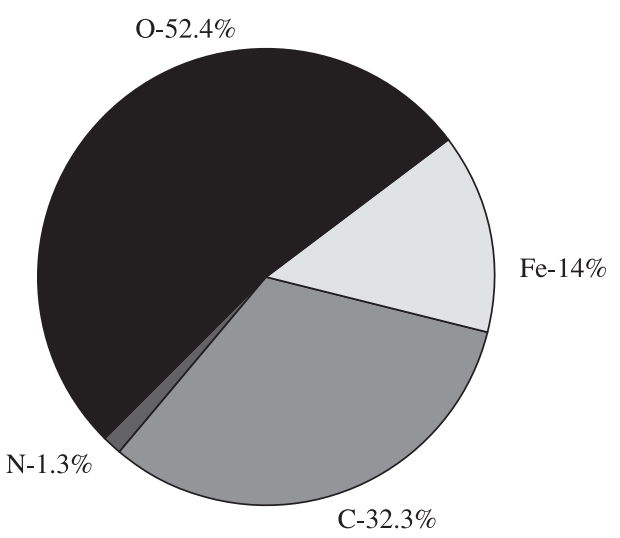

Figure 2. Atomic concentration obtained by X-ray photoelectron spectroscopy from the steel sample.

Table 2. Molecules of 6150 steel surface after each step of pre-treatment.

\begin{tabular}{|c|c|c|c|c|c|c|c|c|c|c|c|c|}
\hline \multirow{2}{*}{ Sample } & \multicolumn{12}{|c|}{ Molecules (\%) } \\
\hline & $\left(\mathrm{Fe}_{3} \mathrm{C}\right)$ & $(\mathrm{C}-\mathrm{H})$ & $(\mathrm{C}-\mathrm{O})$ & $(\mathrm{C}=\mathrm{O})$ & $(\mathrm{O}-\mathrm{C}=\mathrm{O})$ & $\left(\mathrm{Fe}_{3} \mathrm{~N}\right)$ & $\left(\mathrm{Fe}_{3} \mathrm{NC}_{\mathrm{y}}\right)$ & $(\mathrm{C}-\mathrm{N})$ & $(\mathrm{FeO})$ & $(\mathrm{FeOOH})$ & $\left(\mathrm{FeO}_{\mathrm{x}}\right)$ & $\left(\mathrm{Fe}_{2} \mathrm{O}_{3}\right)$ \\
\hline $\mathrm{CN} 1$ & 0.98 & 13.21 & 23.61 & 2.28 & 8.07 & 0.39 & 0.77 & 0.46 & 43.17 & 1.47 & 1.34 & 4.25 \\
\hline $\mathrm{CN} 2$ & 2.12 & 18.06 & 22.22 & 2.52 & 5.73 & 0.46 & 0.64 & 0.60 & 40.35 & 1.54 & 1.18 & 4.47 \\
\hline $\mathrm{CNC}$ & 1.67 & 20.56 & 24.65 & 2.38 & 4.96 & 0.55 & 0.60 & 0.51 & 37.6 & 1.25 & 1.18 & 4.09 \\
\hline CNCE & 1.99 & 20.29 & 26.66 & 2.77 & 2.92 & 0.62 & 0.68 & 0.41 & 37.36 & 1.38 & 1.26 & 4.26 \\
\hline
\end{tabular}




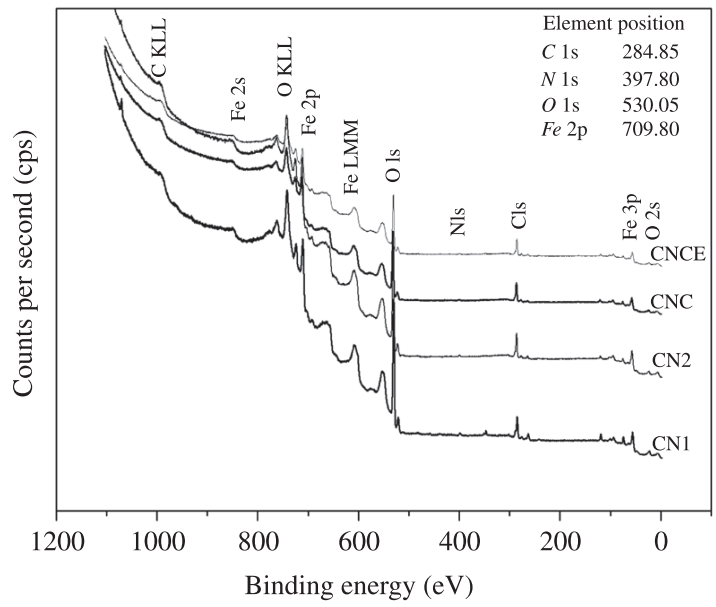

Figure 3. XPS survey spectrum of pre-treatment samples.

the formation of iron carbide and $\mathrm{Fe}_{\mathrm{x}} \mathrm{C}_{\mathrm{y}} \mathrm{N}_{\mathrm{z}}$. Furthermore, it was verified an excess of oxygen, partially involved in connections of $\mathrm{C} 1 \mathrm{~s}$. It may be considered that there is a small component related to iron carbide ( $\mathrm{F}_{3} \mathrm{C}$ to $283.5 \mathrm{eV}$ ). Also, the diffusion of $\mathrm{C}$ in the steel surface layer induced the formation of $\mathrm{Fe}_{3} \mathrm{C}$. The relative intensity contribution of this follows the overall concentration of Fe. In addition, it was found sub-peaks for CO groups (286.5 eV), carbonyl $(288.4 \mathrm{eV})$, and carboxyl $(289.6 \mathrm{eV})$ also detected in $\mathrm{O} 1 \mathrm{~s}$ and $\mathrm{C} 1 \mathrm{~s}$ spectra. This contribution decreased the overall content of oxygen in accordance with the number of stages of carbonitriding. The spectrum in the region of bonding energy of nitrogen shows three peaks with little intensity changed, over the treatments. The low-energy components are related to connections of $\mathrm{Fe}$ and $\mathrm{N}$, which probably are $\mathrm{Fe}_{2,3,4} \mathrm{~N}^{[27]}$. In accordance with the phase, it is more abundant iron $\mathrm{FeO}$ to $709.6 \mathrm{eV}$ than another phase, $\mathrm{FeOOH}$ at $711.2 \mathrm{eV}^{[28]}$. In the oxygen XPS spectra, it appears that the region of the bonding energy spectrum was dominated by oxygen groups of iron oxide $(529.9 \mathrm{eV})$, with minor amounts of the groups $\mathrm{C}-\mathrm{O}, \mathrm{C}=\mathrm{O}$ and $\mathrm{O}-\mathrm{C}=\mathrm{O}^{[29]}$.

\subsection{Raman Spectroscopy of surface bonding chemical}

As the pre-treatment progresses, the D and $G$ characteristics approach those of DLC. Table 3 shows the $\mathrm{I}_{\mathrm{D}} / \mathrm{I}_{\mathrm{G}}$ ratio is 0.74 for sample $\mathrm{CNC}$, compared with for 0.64 from CNCE. This indicates that as a result of these pretreatments, the carbon bonding state evolves from one that is very different from DLC to one that is similar just prior to DLC deposition. This similarity may be an important factor in enhanced coating adhesion ${ }^{30,31}$. Figure 4 shows Raman spectra obtained from steel sample after carbonitriding (CN1 and $\mathrm{CN} 2)$ and after equilibration (CNCE). Table 3 compares the various characteristics associated with the D and G bands obtained from SAE 6150 modified steel samples.

\subsection{Coating adhesion by scratch testing}

The critical load was considered here to be related to the starting point of cohesive failure of the film ${ }^{32}$. Figure 5

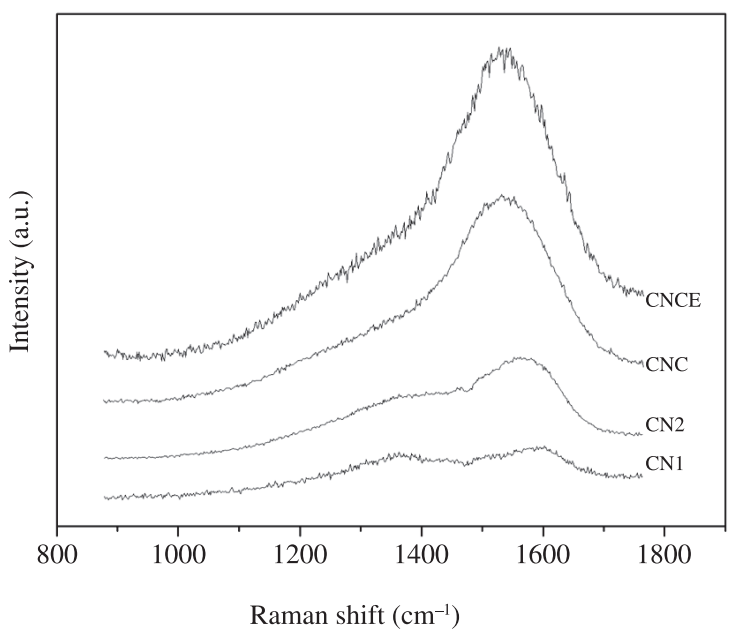

Figure 4. Raman spectra obtained from the steel sample after carbonitriding (CN1 and $\mathrm{CN} 2)$, after slow cooling (CNC) and equilibration (CNCE).

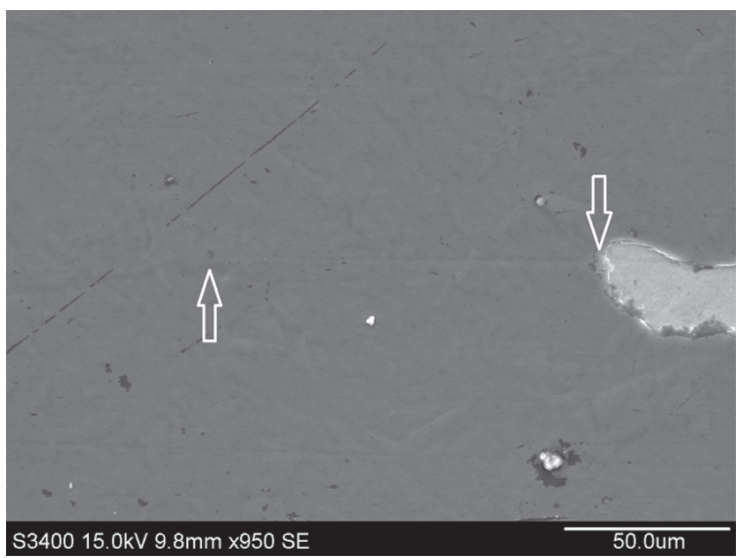

Figure 5. SEM micrograph of a typical scratch track from the beginning to the onset of DLC coating delamination.

Table 3. Comparison of the D and G band characteristics between steel samples after different pre-treatments and DLC.

\begin{tabular}{crrrrr}
\hline \multirow{2}{*}{ Sample } & \multicolumn{2}{c}{$\begin{array}{c}\text { Band Position }\left(\mathbf{c m}^{-1}\right) \\
\text { D G }\end{array}$} & \multicolumn{2}{c}{ FWHM $\left(\mathbf{c m}^{-1}\right)$} & $\mathbf{I}_{\mathbf{D}} / \mathbf{I}_{\mathbf{G}}$ \\
\hline CN1 & 1373.9 & 1586.4 & 269.2 & 122.0 & 1.02 \\
CN2 & 1403.1 & 1573.6 & 329.0 & 125.2 & 0.85 \\
CNC & 1352.3 & 1545.4 & 336.3 & 164.7 & 0.74 \\
CNCE & 1392.8 & 1558.3 & 322.3 & 147.4 & 0.64 \\
\hline
\end{tabular}

shows an SEM image of the scratch track from the initial point of scratch to the beginning of the delamination. The length of the scratch track was measured to be $117 \pm 6 \mu \mathrm{m}$, corresponding to a critical load of $117 \pm 6 \mathrm{mN}$, since the experiment was performed at sliding rate of 1 micron/s and loading rate of $1 \mathrm{mN} / \mathrm{sec}$. Figure 6 shows the diamond indenter depth, friction force, and friction coefficient during scratching. Both the indenter depth and friction force vary smoothly until the onset of delamination, at which a sudden downward displacement of the indenter occurs. The critical 

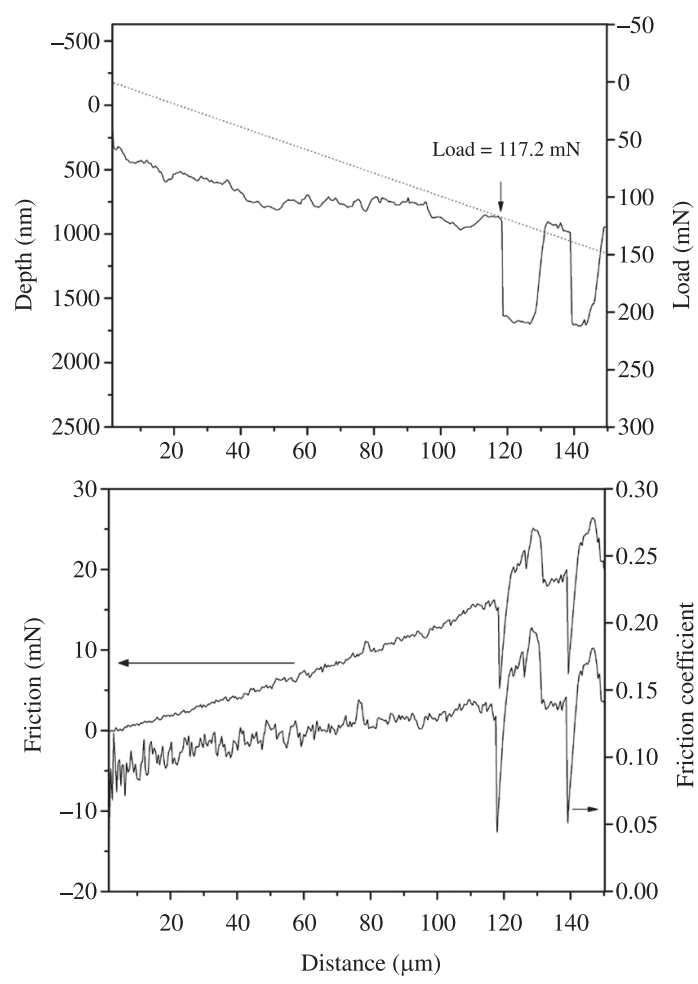

Figure 6. Indenter depth, applied force, friction force, and friction coefficient during diamond scratch testing of one-micron thick DLC-coated steel.

load was measured to be $126 \pm 6 \mathrm{mN}$, consistent with the scratch length measurement. The scratch experiment was repeated three times, and the average critical load for delamination was found to be $121 \pm 6 \mathrm{mN}$. Assuming Hertzian contact and an elastic modulus of $180 \mathrm{GPa}$ for the

\section{References}

1. Vanhulsel A, Velasco F, Jacobs R, Eersels L, Havermans D, Roberts E et al. DLC solid lubricant coatings on ball bearings for space applications. Tribology International. 2007; 40:1186-1194. http://dx.doi.org/10.1016/j. triboint.2006.12.005

2. Mousinho A, Mansano R, Massi M and Jaramillo J. Micro-machine fabrication using diamond-like carbon films. Diamond and Related Materials. 2003; 12:1041-1044. http:// dx.doi.org/10.1016/S0925-9635(02)00219-4

3. Li D and Chung Y. Growth responses of ultrathin CNx overcoats to process parameters. Thin Solid films. 2006; 506-507:207-211. http://dx.doi.org/10.1016/j.tsf.2005.08.013

4. Komatsu Y, Alanazi A and Hirakuri K. Application of diamond-like carbon films to the integrated circuit fabrication process. Diamond and Related Materials. 1999; 8:2018-2021. http://dx.doi.org/10.1016/S0925-9635(99)00138-7

5. Cui F and Li D. A review of investigations on biocompatibility of diamond-like carbon and carbon nitride films. Surface and Coatings Technology. 2000; 131:481-487. http://dx.doi. org/10.1016/S0257-8972(00)00809-4
DLC coating, the shear and tensile stresses at this critical delamination load are $\sim 6.3$ and $2.7 \mathrm{GPa}$, respectively.

\section{Conclusions}

In an effort to show the molecules and atomic concentration on the surface that receive the DLC coating, we used a series of carbonitriding and carburizing steps to modify the composition of 6150 steel substrates, followed by DLC coating deposition. These pre-treatment steps resulted in a surface with a composition with $\mathrm{Fe}, \mathrm{N}, \mathrm{C}$ and $\mathrm{O}$ elements. X-ray diffraction showed the formation of various hard carbide and nitride phases due to such pre-treatments. The phases of nitride and carbide formed are consistent with the extent of carbon and nitrogen diffusion in bcc iron at the pre-treatment temperature. XPS analyzes show: (1) On the surface were not verified concentrations of $\mathrm{V}, \mathrm{Cr}, \mathrm{Mn}$ and $\mathrm{S}$, however, $\mathrm{C}, \mathrm{O}, \mathrm{N}$ and Fe were verified; (2) Most of molecules found on the surface contained oxygen, although the most important molecules generated in the surface from the process were $\mathrm{Fe}_{3} \mathrm{~N}, \mathrm{Fe}_{\mathrm{x}} \mathrm{C}_{\mathrm{y}} \mathrm{N}_{\mathrm{z}}, \mathrm{CN}_{\mathrm{x}}$ and, $\mathrm{Fe}_{3} \mathrm{C}$; (3) It was found that the step of carbonitriding (CN1 and CN2) modify the surface chemical structure, and subsequently step at cooling steady state (CNC) maintained it, occurring significant concentrations of carburizing $\mathrm{Fe}_{3} \mathrm{C}$ in step further (CNCE). It is important to remember that the oxygen present in the deposition system contributes to the formation of oxide molecules. Raman spectroscopy showed that the modified steel surface just before DLC deposition exhibits local carbon bonding characteristics similar to DLC, thus promoting adhesion. Subsequent DLC deposition by the pulsed PECVD technique resulted in a coating with relatively good adhesion on SAE 6150 steel.

\section{Acknowledgements}

The financial support of Fundação de Amparo à pesquisa de Minas Gerais-FAPEMIG is gratefully acknowledged.

6. Yeldose B and Ramamoorthy B. Characterization of DC magnetron sputtered diamond-like carbon (DLC) nano coating. International Journal of Advanced Manufacturing Technology. 2008; 8:705-717. http://dx.doi.org/10.1007/ s00170-007-1131-8

7. Trava-Airoldi V, Bonetti L, Capote G, Santos L and Corat E. A comparison of DLC film properties obtained by r.f. PACVD, IBAD and enhanced pulsed-DC PACVD. Surface and Coatings Technology. 2007; 202:549-554. http://dx.doi.org/10.1016/j. surfcoat.2007.06.030

8. Grill A. Diamond-like carbon: state of the art. Diamond and Related Materials. 1999; 8:428-434. http://dx.doi.org/10.1016/ S0925-9635(98)00262-3

9. Chang Cand Wang D. Microstructure and adhesion characteristics of diamond-like carbon films deposited on steel substrates. Diamond and Related Materials. 2001; 10:1528-1534. http:// dx.doi.org/10.1016/S0925-9635(01)00382-X

10. Chen K and Lin J. The study of adhesion and nanomechanical properties of DLC films deposited on tool steels. Thin Solid Films. 2009; 517:4916-4920. http://dx.doi.org/10.1016/j. tsf.2009.03.124 
11. Sheeja D, Tay B, Leong K and Lee C. Effect of film thickness on the stress and adhesion of diamond-like carbon coatings. Diamond and Related Materials. 2002; 11:1643-1647. http:// dx.doi.org/10.1016/S0925-9635(02)00109-7

12. Ager III J, Anders S, Brown I, Nastasi M and Walter K. Multilayer hard carbon films with low wear rates. Surface and Coatings Technology. 1997; 91:91-94. http://dx.doi. org/10.1016/S0257-8972(97)80004-7

13. Trava-Airoldi V, Bonetti, Capote G, Fernandes J, Blando $\mathrm{E}$, Hübler $\mathrm{R}$ et al. DLC film properties obtained by a low cost and modified pulsed-DC discharge. Thin Solid Films. 2007; 516:272-276. http://dx.doi.org/10.1016/j. tsf.2007.06.100

14. Jeong G, Hwang M, Jeong B, Kim M and Lee C. Effects of the duty factor on the surface characteristics of the plasma nitrided and diamond-like carbon coated high-speed steels. Surface and Coatings Technology. 2000; 124:222-227. http://dx.doi. org/10.1016/S0257-8972(99)00648-9

15. Kim H, Moon M, Kim D, Lee K and Oh K. Observation of the failure mechanism for diamond-like carbon film on stainless steel under tensile loading. Scripta Materialia. 2007; 57:1016-1019. http://dx.doi.org/10.1016/j.scriptamat.2007.07.042

16. Silva W, Trava-Airoldi V and Chung Y. Surface modification of 6150 steel substrates for the deposition of thick and adherent diamond-like carbon coatings. Surface and Coatings Technology. 2011; 205:3703-3707. http://dx.doi.org/10.1016/j. surfcoat.2011.01.013

17. Cahn $J$ and Hilliard. Free Energy of a Nonuniform System. I. Interfacial Free Energy. Journal of Chemical Physics. 1958;28:258-267. http://dx.doi.org/10.1063/1.1744102

18. Dasgupta A, Kuppusami P, Vijayalakshmi M and Raghunathan V. Pulsed plasma nitriding of large components and coupons of chrome plated SS316LN stainless steel. Journal of Materials Science. 2007; 42:8447-8453. http://dx.doi.org/10.1007/ s10853-007-1783-7

19. Mori $H$ and Tachikawa $H$. Increased adhesion of diamond-like carbon-Si coatings and its tribological properties. Surface and Coating Technology. 2002; 149:225-230. http://dx.doi. org/10.1016/S0257-8972(01)01449-9

20. Silva W, Ferreira N, Travello J, Almeida E, Azevedo A and Baldan M. Dependence of diamond nucleation and growth through graphite etching at different temperatures. Diamond and Related Materials. 2007; 16:1705-1710. http://dx.doi. org/10.1016/j.diamond.2007.05.004

21. Fattah M and Mahboubi F. Comparison of ferritic and austenitic plasma nitriding and nitrocarburizing behavior of AISI 4140 low alloy steel. Materials and Design. 2010; 31:3915-3921. http://dx.doi.org/10.1016/j.matdes.2010.03.008
22. Forsich C, Heim D and Mueller T. Influence of the deposition temperature on mechanical and tribological properties of a-C:H:Si coatings on nitrided and postoxidized steel deposited by DC-PACVD. Surface and Coatings Technology. 2008; 203:521-525. http://dx.doi.org/10.1016/j. surfcoat.2008.05.044

23. Chen K, Lin J, Tsai W and Ai C. Plasma immersion ion implantation induced improvements of mechanical properties, wear resistance, and adhesion of diamond-like carbon films deposited on tool steel. Surface and Coatings Technology. 2009; 204:229-236. http://dx.doi.org/10.1016/j. surfcoat.2009.06.033

24. Rovere C, Alano J, Silva R, Nascente P, Otubo J and Kuri S. Influence of alloying elements on the corrosion properties of shape memory stainless steels. Materials Chemistry and Physics. 2012; 133:668-673. http://dx.doi.org/10.1016/j. matchemphys.2012.01.049

25. Barbosa D, Hammer P, Trava-Airoldi V and Corat E. The valuable role of renucleation rate in ultrananocrystalline diamond growth. Diamond and Related Materials. 2012; 23:112-119. http://dx.doi.org/10.1016/j.diamond.2012.01.028

26. Cooper L, Benhaddad S, Wood A and Iveya D. The effect of surface treatment on the oxidation of ferritic stainless steels used for solid oxide fuel cell interconnects. Journal of Power Sources. 2008; 184:220-228. http://dx.doi.org/10.1016/j. jpowsour.2008.06.010

27. Gontijo L, Machado R, Miola E, Casteletti L and Nascente P. Characterization of plasma-nitrided iron by XRD, SEM and XPS. Surface and Coatings Technology. 2004; 183:10-17. http://dx.doi.org/10.1016/j.surfcoat.2003.06.026

28. Barshilia H, Ananth A, Khan J and Srinivas G. Ar $+\mathrm{H}_{2}$ plasma etching for improved adhesion of PVD coatings on steel substrates. Vacuum. 2012; 86:1165-1173. http://dx.doi. org/10.1016/j.vacuum.2011.10.028

29. Filik J, Maya P, Pearce S, Wild R and Hallam K. XPS and laser Raman analysis of hydrogenated amorphous carbon films. Diamond and Related Materials. 2003; 12:974-978. http:// dx.doi.org/10.1016/S0925-9635(02)00374-6

30. Ferrari A. Determination of bonding in diamond-like carbon by Raman spectroscopy. Diamond and Related Materials. 2002; 11:1053-1061. http://dx.doi.org/10.1016/ S0925-9635(01)00730-0

31. Robertson J. Mechanism of $\mathrm{sp}^{3}$ bond formation in the growth of diamond-like carbon. Diamond and Related Materials. 2005; 14:942-948. http://dx.doi.org/10.1016/j. diamond.2004.11.028

32. Holmberg K, Matthews A and Ronkainen H. Coatings tribology-contact mechanisms and surface design. Tribology International. 1998; 31:107-120. http://dx.doi.org/10.1016/ S0301-679X(98)00013-9 